\title{
Mechanisms and field test of solution mining by self-resonating cavitating water jets
}

\author{
Song Xianzhi', Li Gensheng ${ }^{1 *}$, Yuan Jinping ${ }^{1,2}$, Tian Zhonglan², \\ Shen Ruichen ${ }^{2}$, Yuan Guangjie ${ }^{2}$ and Huang Zhongwei ${ }^{1}$ \\ ${ }^{1}$ State Key Laboratory of Petroleum Resource and Prospecting, China University of Petroleum, Beijing 102249, China \\ ${ }^{2}$ Drilling Engineering Research Institute, CNPC, Beijing 100088, China
}

(C) China University of Petroleum (Beijing) and Springer-Verlag Berlin Heidelberg 2010

\begin{abstract}
Rapid solution mining is the key to cavern construction in salt formations. Rapid solution mining technology with self-resonating cavitating water jets is described in this paper. It can generate three main physical effects: helical flow dissolution, self-resonating cavitating jet erosion, and ultrasonic waves. A self-resonating cavitating nozzle was also designed with the principles based on theory of fluid transients and hydro-acoustics. Under ambient pressure, the experimental results show that the impulse amplitude of pressure reaches a peak at a standoff distance of 5-13 times the nozzle outlet diameter and the cutting ability of self-resonating cavitating jets is twice that of conventional jets under the same conditions. Compared with the conventional mining method, the field test indicates that rapid solution mining technology with self-resonating cavitating jets can speed the construction by more than 2 times at the pocket stage of cavern development.
\end{abstract}

Key words: Cavitating jet, underground storage, helical flow, rapid solution, salt cavern

\section{Introduction}

The West-East Natural Gas Pipeline, which transports gas to the eastern provinces from the Tarim Basin in Xinjiang, the Qaidam Basin in Qinghai, and the Shaanxi-Ningxia-Gansu Basin, is under construction. Salt cavern gas storage will provide essential support for this project (Tian and Zhang, 2005; Ding and Xie, 2006). Natural gas storage in salt caverns is meeting the need for flexible, high injection and delivery storage, ensuring natural gas emergency requirements and seasonal needs (Beutel and Black, 2005; Stopa et al, 2008). Construction of salt caverns requires finding an appropriate salt dome or salt bed, drilling a well into the formation, and injecting fresh water to dissolve and extract a certain amount of salt to get the required volume and shape (Barron, 1994; Ban and Gao, 2007). The initial stage of solution mining is the pocket construction stage with poor delivery rate and low brine water concentration. Conventional solution mining methods have to depend on high consumption of fresh water, long operation duration and expensive costs in this period. In order to reduce time and expenditure on construction of salt caverns and ensure gas-supply safety in the WestEast gas pipeline project, it is necessary to study urgently the mechanism and techniques of rapid salt cavern solution mining technology at the pocket construction stage.

The self-resonating cavitating jet is a new type of

*Corresponding author. email: ligs@cup.edu.cn

Received January 16, 2009 jet with strong pressure oscillation and high cavitation inception characteristics ( $\mathrm{Li}$ et al, 2005). It is modulated by a continuous jet, explained by the theory of fluid transients that describes the transition of small turbulent wave in the pipe, and the principle of fluid self-sustained oscillation of hydro-acoustics ( $\mathrm{Li}$ and Shen, 1996). The jet has the big ring vortexes and strong pressure oscillation. Under the conditions of atmospheric pressure and ambient pressure the cavitating jet has higher cavitation inception, strong pressure oscillation, and higher rock cutting ability, when compared with the conventional jet (Conn and Rudy 1976; Yi et al, 2005).

In order to achieve rapid solution mining at the pocket construction stage, a rapid solution mining tool was developed based on the self-resonating cavitating jet theory and damping rotation control technique.

Fig. 1 shows the schematic diagram of the tool and fluid circulation. It consists of a filter, one-way valve, damper, rotary jet system, and self-resonating cavitating nozzles. The tool connects the tubing and travels into the salt cavern. Fresh water is pumped through the tubing, filter, one-way valve, and cavitating nozzles to generate four lateral self-resonating cavitating jets, which are inclined to drive and rotate the tool, and impact the rock salt intensely. After salt dissolution and diffusion, the fresh water becomes brine and is circulated out of the cavern through the annulus between tubing and casing. Meanwhile, the pipe is moved up and down so that the solution of the salt cavern could be all-around by powerful water jets until the required size is obtained. 


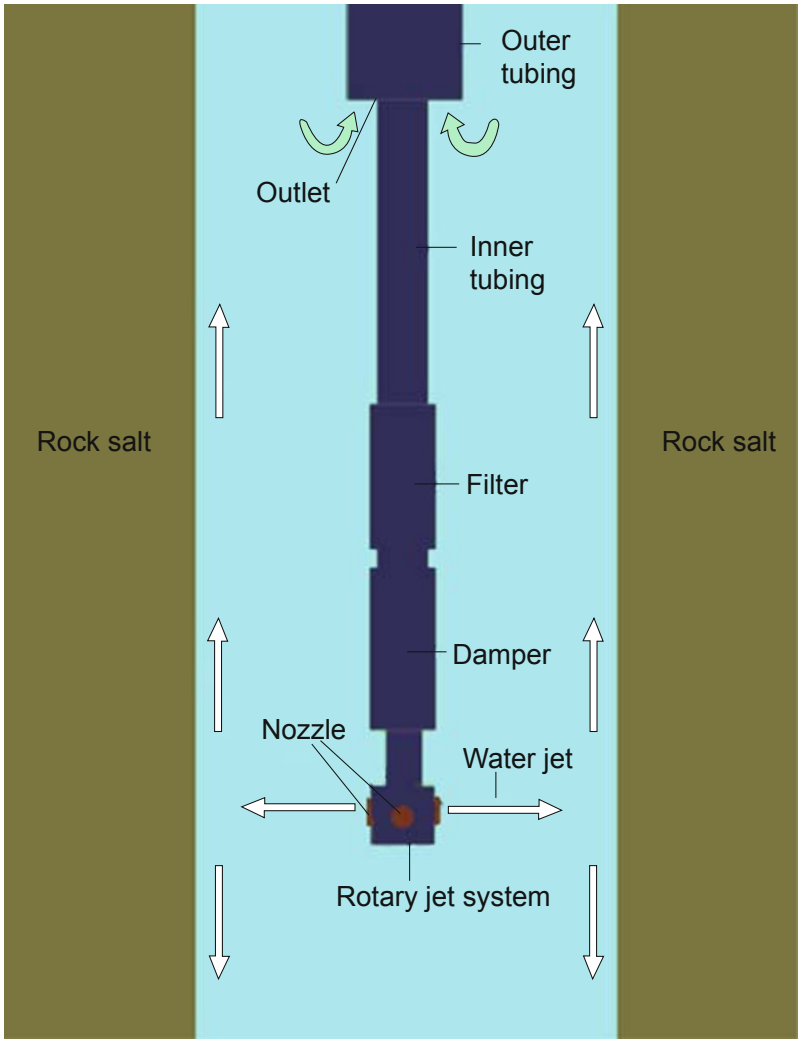

Fig. 1 Schematic diagram of the tool and fluid circulation

\section{Mechanisms of the rapid solution mining tool}

The rapid solution mining tool can generate three main physical effects: helical flow dissolution, self-resonating cavitating jet erosion and supersonic waves.

\subsection{Helical flow dissolution}

During the process of solution mining, the jet system rotates automatically at a speed of $100-400 \mathrm{r} / \mathrm{min}$ by the torque of four tangential high-pressure water jets (Fig. 2), which are controlled by a damper. The action of the lateral water jets rotating as four agitator arms rotates the fluids in the cavern as a helical flow with a vertical rotation axis (Fig. 3 ). The fluid velocity on the surface of the rock salt increases and the flow direction can be changed, enhancing the mass transfer of salt molecules near the wall. The process also improves the flow pattern of brine in the cavern, increasing
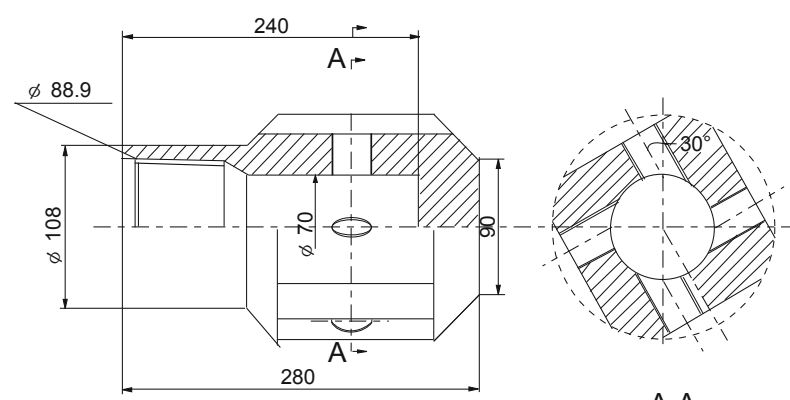

A-A the convective diffusion of saturated brine. Meanwhile, the fresh water is delivered to the rock salt surface directly by the high-pressure water jet, which improves the concentration distribution of brine and enhances the convective diffusion of saturated brine near the wall. Hence, on the impact of helical flow, the salt dissolution rate increases dramatically and the speed of salt cavern construction enhances greatly.

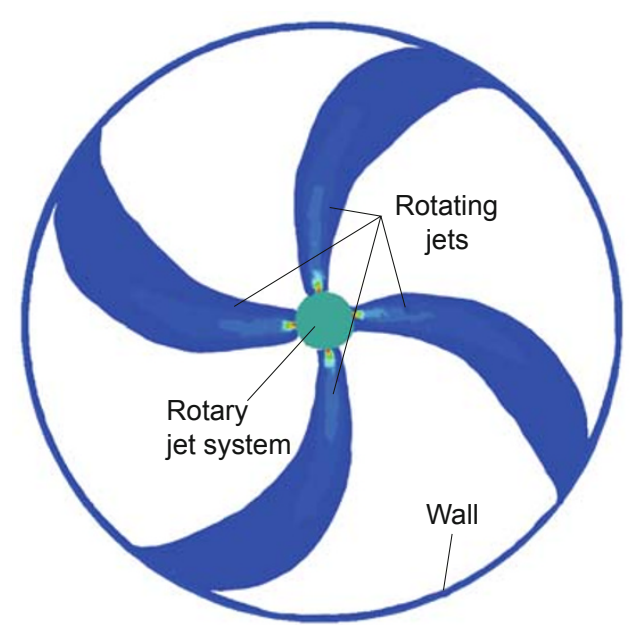

Fig. 3 Schematic diagram of four high-pressure water jets rotating as hydraulic agitators

\subsection{Self-resonating cavitating jet erosion}

The self-resonating cavitating jets have more intense pressure oscillation and better rock erosion efficiency than standard jets (Conn and Rudy 1976). At atmospheric pressure, the rock erosion rate is two to four times higher than the conventional jets (Yi et al, 2005). Fig. 4 shows the effect of four powerful hydraulic pulses on the wall at every circle, and each self-resonating cavitating jet is a high frequency oscillating jet (Fig. 5). Repeated powerful pulse impact leads to the formation of micro-fractures on the wall, and sometimes the breaking of rock salt. The micro-fracture propagation and water jet penetration increases the rate of salt dissolution. In addition, the self-resonating cavitating water jet has high cavitation inception ability, so cavitating bubbles form, travel and collapse along with the jet. The collapse of bubbles generates transient pressure 8.6-124 times higher than jet impact pressure in a few microseconds and also breaks the rock salt directly (Conn and Rudy 1976).

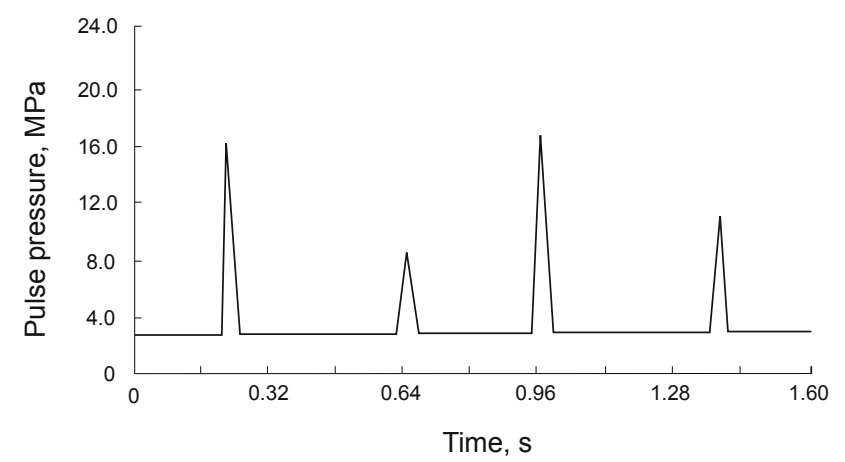

Fig. 4 Pulse pressure of four hydraulic impacts on the cavern wall

Fig. 2 Schematics of the jet unit 


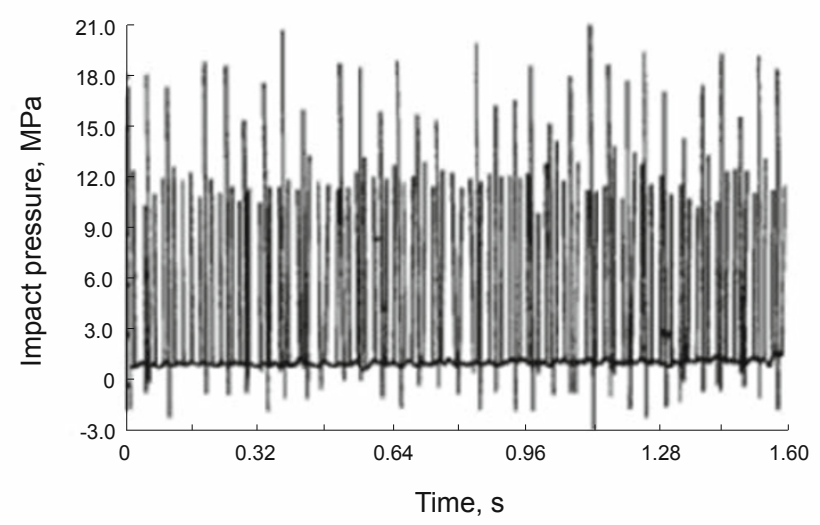

Fig. 5 High frequency oscillating pressure of self-resonating cavitating jet

\subsection{Supersonic wave}

A self-resonating cavitating jet can generate high frequency and high intensity focused ultrasonic waves, which produce lower brine viscosity, better flow ability and a higher mass transfer rate (Brujan et al, 2005). Besides, the noise wave impact on the rock salt surface also causes fatigue fractures, which can increase the salt dissolution rate. Moreover, the energy from noise transferring to the salt surface potentially creates severe vibration and accelerates the salt diffusion.

\section{Design of self-resonating cavitating nozzles}

The basic principle of a self-resonating cavitating jet is based on the theory of fluid transients and hydro-acoustics. The organ pipe as a typical self-resonating chamber is shown in Fig. 6. Acoustic analyses and experimentation ( $\mathrm{Li}$ and Shen, 1992) have led to the following approximation, useful for estimating the length of the organ-pipe:

$$
L=\frac{K_{\mathrm{N}} \cdot d}{M \cdot S_{\mathrm{d}}}
$$

where $L$ is the length of the organ-pipe, $\mathrm{mm} ; d$ is the diameter of the nozzle outlet, $\mathrm{mm} ; S_{\mathrm{d}}$ is the critical Strouhal number, dimensionless; $M$ is the operating Mach number, dimensionless; $K_{\mathrm{N}}$ is the model parameter.

The optimum erosion result can be obtained from the organ-pipe nozzle, when $M$ is from 0.08 to 0.09 and $S_{\mathrm{d}}$ is 0.3 (Li and Shen, 1992). The designed self-resonating cavitating nozzles were used in the following experiments and field tests.

Using the 178-mm (OD) casing and 114-mm (OD) tubing for the pocket stage and various flow rates $\left(35-55 \mathrm{~m}^{3} / \mathrm{h}\right)$ with pump pressures ranging from 13 to $16 \mathrm{MPa}$, the optimum equivalent nozzle diameter was calculated. Nozzles with an outlet diameter of 4, 5 and $6 \mathrm{~mm}$ were selected for both laboratory experiments and field tests in this study.

\section{Characteristics of impact pressure and rock erosion by self-resonating cavitating jets}

When a self-resonating cavitating jet is used to cut rock

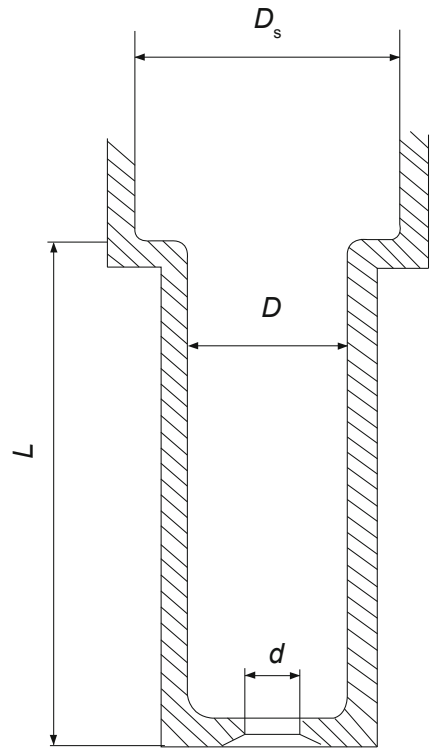

Fig. 6 Schematic of an organ-pipe self-resonating chamber

during drilling a wellbore, the ambient pressure is one of the most important factors influencing the jet characteristics. A set of experiments was conducted to study the characteristics of impact pressure and rock volume cut by the self-resonating cavitating jets under the ambient pressure.

Fig. 7 shows the amplitudes of axial pressure fluctuation of a water jet ejected from the organ-pipe nozzle versus standoff distance under different ambient pressures when the nozzle pressure drop was $8.0 \mathrm{MPa}$ and the nozzle outlet diameter $5.0 \mathrm{~mm}$. This figure shows that the peak fluctuation of the axial pressure of the self-resonating jets under different ambient pressures was observed at the distance of 5-13 times the nozzle diameter. With an increase in the ambient pressure $\left(p_{\mathrm{a}}\right)$, the optimum standoff distance increased and the peak amplitude of the oscillation declined.

Experiments on the eroding ability (or cutting ability) of the water jet from the organ-pipe nozzles and from conventional nozzles were conducted on artificial sandstones. Fig. 8 presents the erosion curves when the nozzle pressure drop was $40 \mathrm{MPa}$ and the standoff distance was $6 \mathrm{~mm}$. This figure shows that the rock volume eroded or cut by cavitating jets decreased with an increase in the ambient pressure. This

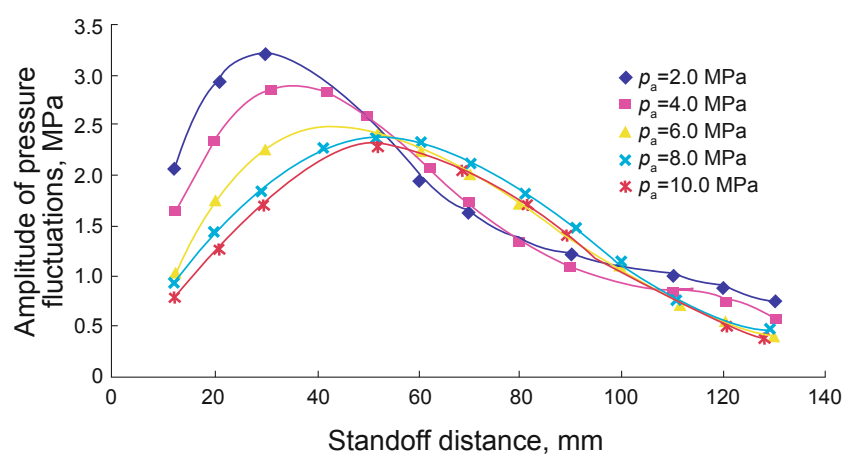

Fig. 7 Amplitude of axial pressure fluctuation of water jets ejected from the organ-pipe nozzle under different ambient pressures 
is because the resonance amplitude and cavitation effect decreased as the ambient pressure increased. Within the range of ambient pressure adopted in the tests, the water jets eject from organ-pipe nozzles had higher eroding or cutting ability than those ejected from conventional nozzles. Compared with the cumulative eroded rock volume, the eroding or cutting ability of the water jet from organ-pipe nozzles was 1 to 2 times those from conventional nozzles under the same conditions.

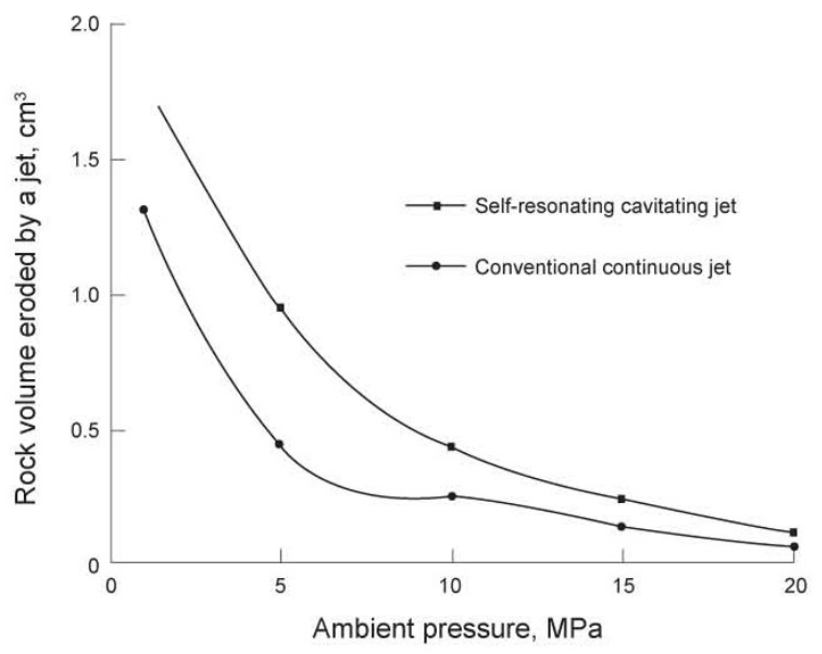

Fig. 8 Variation of eroded rock volume with ambient pressure

\section{Field tests}

The rapid solution mining tool was tested at the pocket construction stage in the JZ1 well, which is located at Jintan city, Jiangsu Province (Fig. 9). The JZ1 well was a pilot test well, through which a salt cavern was constructed by injecting water to dissolve an underground salt dome with the rapid solution mining technique. The rock salt was discovered at a depth of 945 to $1,186 \mathrm{~m}$, with a layer thickness of $241 \mathrm{~m}$. Material analyses showed that the salt formation contained about 13.4 percent insoluble matter made up of interlayers about $4.2 \mathrm{~m}$ thick.

The C 5 well was chosen as a reference well, in which the salt was dissolved by the conventional method. The chemistry of the produced brine, bed thickness and total depth of the salt formation in both C5 and JZ1 wells were identical. Hence, the JZ1 well was expected to perform in the similar way as the C5 well, except for the beneficial effects of the self-resonating cavitating water jets. A comparison of the salt production rate from the $\mathrm{C} 5$ and JZ1 wells is presented in Fig. 10, which indicates that the hourly salt production of the JZ1 well was much higher than that observed in well C5. It can be seen that an increase up to a factor of three was attained. Furthermore, Fig. 11 shows a comparison of cumulative salt production for both wells. In the initial 11 days, the cumulative salt production of C5 well was 375 tonnes and that of JZ1 well was 870 tonnes, 2.3 times as much. As a conclusion, compared with the conventional method, the rapid solution mining technology can increase the construction rate by a factor of two (or more) in the pocket stage.

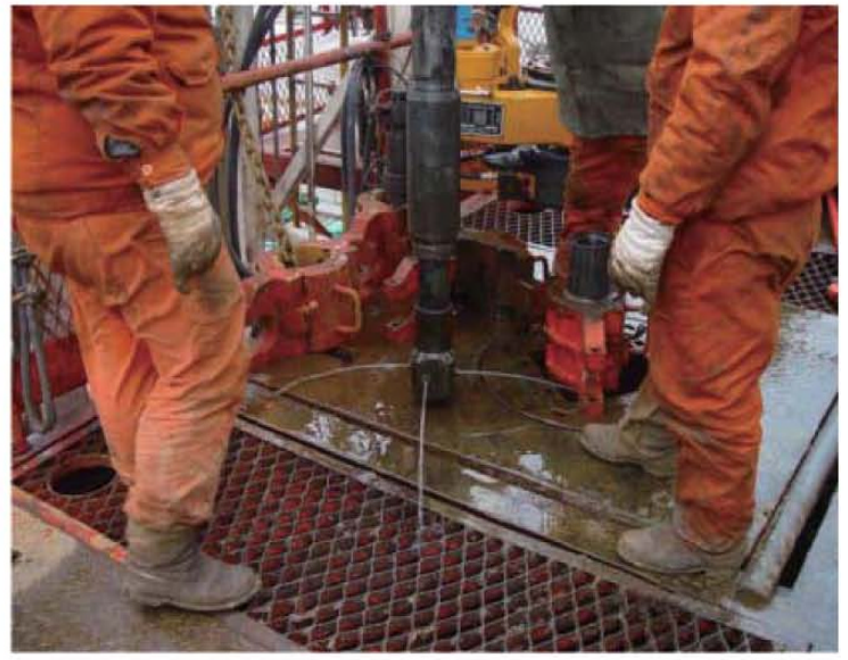

Fig. 9 Field test of rapid solution mining tool

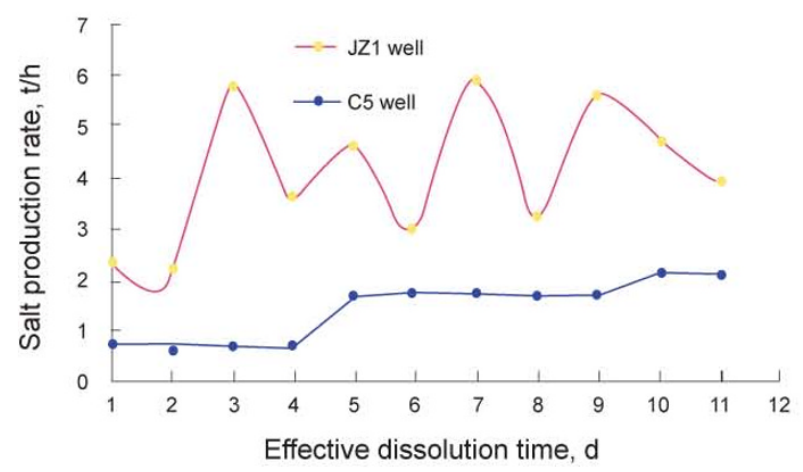

Fig. 10 Comparison of salt production rate from JZ1 and C5 wells

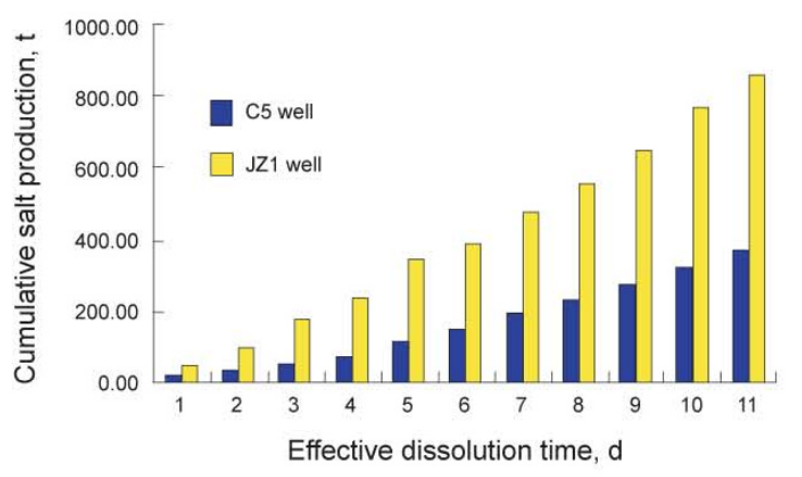

Fig. 11 Comparison of cumulative salt production data

\section{Conclusions}

1) The rapid solution mining tool generates three main physical effects: hydraulic impact of rotary jets, highfrequency self-excited jet impact and cavitating noise, which can greatly increase the salt dissolution rate and shorten the cavern construction duration in the pocket stage.

2) At ambient pressure, the maximum amplitude of oscillating pressure of self-resonating cavitating jets is reached at a standoff distance of 5-13 times the nozzle 
diameter, and the rock eroding or cutting ability of selfresonating cavitating jets is 1 to 2 times that of conventional jets.

3) The field test indicates that the rapid solution mining tool would increase the salt production rate dramatically compared with the conventional method. Especially in the pocket construction stage, the construction rate would be increased two-fold.

4) The rapid solution mining technology with selfresonating cavitating jets has advantages such as high utilization ratio of hydraulic energy, rapid salt dissolution rate, and good adaptability with other dissolution methods. This technology can significantly improve the construction of salt cavern storage for the West to East Gas Pipeline Project.

\section{Acknowledgements}

The authors are grateful for financial support from the Projects of EU-CHINA Energy and Environment Program (Europe Aid-120723-D-SV-CN) and the Ph.D Programs Foundation of Ministry of Education of China (No. 20070425006).

\section{References}

Ban F S and Gao S S. Research on design proposal optimization of salt cavern gas storage building with water solution. Natural Gas Industry. 2007. 27(2): 114-116 (in Chinese)

Barron T F. Regulatory, technical pressures prompt more U. S. saltcavern gas storage. Oil \& Gas Journal. 1994. 92 (37):55-67.

Beutel T H and Black S T. Salt deposits and gas cavern storage in the
UK with a case study of salt exploration from Cheshire. Oil GasEuropean Magazine. 2005. 31(1): 31-35

Brujan E A, Ikeda T and Matsumoto Y. Jet formation and shock wave emission during collapse of ultrasound-induced cavitating bubbles and their role in the therapeutic applications of high-intensity focused ultrasound. Physics in Medicine and Biology. 2005. 50(20): 4797-4809.

Conn A F and Rudy S L. Cutting coal with the CAVIJET cavitating water jet method. Proceedings of 3rd International Symposium on Jet Cutting Technology, Chicago, 1976

Ding G S and Xie P. Current situation and prospect of Chinese underground natural gas storage. Natural Gas Industry. 2006. 26(6): 111-113 (in Chinese)

Li G S and Shen Z H. Design principle of organ-pipe cavitating jet nozzles. Journal of China University of Petroleum (Edition of Natural Science). 1992. 16(5): 35-39 (in Chinese)

Li G S and Shen Z H. Investigation and application of cavitating water jet in drilling. Petroleum Drilling Techniques. 1996. 24(4): 51-54 (in Chinese)

Li G S, Shen Z H, Zhou C S, et al. Advances in investigation and application of self-resonating cavitating water jet. Engineering Science. 2005. 7(1): 27-32 (in Chinese)

Stopa J, Rychlicki S and Kosowski P. The role of salt caverns in underground gas storage. Gospodarka Surowcami MineralnymiMineral Resources Management. 2008. 24(3): 11-23

Tian Z L and Zhang F. Technology of utilization and modification of brine-extracted caverns in Jingtan salt mine. China Well and Rock Salt. 2005. 36(2): 17-20 (in Chinese)

Yi C, Li G S and Zhang D G. Experimental study of enhancing cavitating effect with self-resonating nozzle. China Mechanical Engineering. 2005. 16(21): 1945-1949 (in Chinese)

(Edited by Sun Yanhua) 